\title{
The association between PaTz and improved palliative care in the primary care setting: a cross-sectional survey
}

Ian Koper ${ }^{*}(\mathbb{D}$, H. Roeline W. Pasman, Annicka G. M. Van der Plas, Bart P. M. Schweitzer and

Bregje D. Onwuteaka-Philipsen

\begin{abstract}
Background: The PaTz-method (acronym for Palliatieve Thuiszorg, palliative care at home) is perceived to improve coordination, continuity and communication in palliative care in the Netherlands. Although important for further implementation, research showing a clear effect of PaTz on patient-related outcomes is scarce. This study aimed to examine perceived barriers and added value of PaTz and its association with improved care outcomes.

Methods: Ninety-eight Dutch general practitioners and 229 Dutch district nurses filled out an online questionnaire with structured questions on added value and barrier perception of PaTz-participation, and palliative care provided to their most recently deceased patient, distributed online by Dutch medical and nurses' associations. Data from PaTz-participants and non-participants was compared using Chi-square tests, independent t-tests and logistic regression analyses.

Results: While both PaTz-participants and non-participants perceived PaTz to be beneficial for knowledge collaboration, coordination and continuity of care, time (or lack thereof) is considered the most important barrier for participation. PaTz-participation is associated with discussing five or more end-of-life topics with patients $(\mathrm{OR}=$ 3.16) and with another healthcare provider $(\mathrm{OR}=2.55)$. PaTz-participation is also associated with discussing palliative sedation $(\mathrm{OR}=3.85)$ and euthanasia $(\mathrm{OR}=2.97)$ with another healthcare provider. Significant associations with other care outcomes were not found.

Conclusions: General practitioners and district nurses feel that participating in a PaTz-group has benefits, but perceive various barriers for participation. While participating in a PaTz-group is associated with improved communication between healthcare providers and with patients, the effect on patient outcomes remains unclear. To stimulate further implementation, future research should focus on the effect of PaTz on tangible care characteristics and how to facilitate participation and remove barriers.
\end{abstract}

Keywords: Health care surveys, Interprofessional relations, Palliative care, Primary health care, Professional-patient relations, Quality of care

\footnotetext{
* Correspondence: i.koper@amsterdamumc.nl

Department of Public and Occupational Health, Amsterdam Public Health research institute, Amsterdam UMC, Vrije Universiteit Amsterdam, Van der Boechorststraat 7, 1081BT Amsterdam, The Netherlands
}

(c) The Author(s). 2019 Open Access This article is distributed under the terms of the Creative Commons Attribution 4.0 International License (http://creativecommons.org/licenses/by/4.0/), which permits unrestricted use, distribution, and reproduction in any medium, provided you give appropriate credit to the original author(s) and the source, provide a link to the Creative Commons license, and indicate if changes were made. The Creative Commons Public Domain Dedication waiver (http://creativecommons.org/publicdomain/zero/1.0/) applies to the data made available in this article, unless otherwise stated. 


\section{Background}

Palliative care, an approach aimed to improve quality of life of patients with a life-threatening illness and their relatives, is complex, focusing on the prevention and relief of suffering from physical, psychosocial, and spiritual issues at the end of life [1]. Contrary to many other western countries like the US, Canada, the UK and Australia, palliative care is not a medical specialty in the Netherlands [2]. It is one of few countries where palliative care is provided in a coordinated care model [3] and national policy states that palliative care should principally be provided by generalists close to patients [4]. In practice, it is often provided by Dutch general practitioners (GPs, in some countries better known as family physicians), who can rely on national guidelines on palliative care provision [5], and on supportive services and facilities such as palliative care consultation teams [6]. However, the ageing population and the increasing numbers of non-acute deaths are likely to lead to a higher demand of palliative care [7], and as GPs are already facing a heavy case-load $[8,9]$, the provision of good palliative care may be under threat. Furthermore, while multidisciplinary collaboration has shown to be crucial in the delivery of palliative care [10], this is hampered by financial constraints, poor communication and a lack of time [11]. In addition, while communication with patients with a life-threatening disease and relatives on end-of-life topics has consistently been shown to improve quality of care [12-14], GPs struggle to have these conversations with their patients [15].

In recent years, $\mathrm{PaTz},{ }^{1}$ a method aimed to improve palliative care through early identification of palliative patients, early assessment of their needs, symptoms and preferences, and planning care accordingly, has been implemented in the Netherlands. PaTz is an adaption of the British Gold Standards Framework (GSF), a programme aimed at optimising end of life care provision by generalists in all settings including primary care, which has been shown to improve multidisciplinary collaboration, and the consistency and reliability of palliative care in primary care [16]. In local PaTz-groups, GPs and district nurses (DNs, in some countries better known as community nurses) meet bimonthly to identify and discuss their patients with support from a palliative care consultant (a physician or nurse with formal training in palliative care) [17]. A qualitative evaluation study showed that, like the GSF, PaTz is beneficial to healthcare providers: participants felt that it improved cooperation between GPs and DNs, and that it led to better continuity of care, more knowledge on palliative care, and emotional support [17]. A more recent prepost evaluation study showed again that GPs felt that

${ }^{1} \mathrm{PaTz}$ is an acronym for PAlliatieve ThuisZorg (palliative care at home) continuity and coordination of care as well as their own competence to provide palliative care improved after implementation of $\mathrm{PaTz}$ [18].

Implementation of $\mathrm{PaTz}$ has progressed from four groups at the start in 2012 to more than 160 groups at present. But, as these groups cover only a small part of primary care, further implementation is necessary to improve palliative care in the home setting nationwide. Successful implementation requires understanding of possible barriers for participation, the perceived added value of $\mathrm{PaTz}$, and evidence of the effect on patient related outcomes [19]. However, again like the GSF [20], research showing a clear effect on patient-related outcomes is scarce. The abovementioned pre-post evaluation study also examined the effect of $\mathrm{PaTz}$ on aspects of care that are considered important in quality of palliative care: GPs' awareness of preferred place of death, hospital admission in the final month, treatment goals and GP-patient communication [4, 21-25], but failed to show differences between GPs who did or did not participate in a PaTz group [18]. As some differences were found between patients who were or were not on the PaTz-register or discussed in a PaTz meeting, the authors suggested this might be related to underuse of these important elements of PaTz. Further, they indicated the high level of palliative care before implementation among GPs interested in participating in $\mathrm{PaTz}$ might have been influential: a so-called 'ceiling effect'. The authors recommended therefore including a control group in future studies to be able to account for the latter.

Thus, in order to facilitate further implementation of $\mathrm{PaTz}$, this study first aims to compare PaTz-participants' perceptions of the added value of $\mathrm{PaTz}$ and barriers for participating in $\mathrm{PaTz}$ with non-participants' perceptions. As the roles of GPs and DNs in PaTz-groups differ, and the added value and barriers for participation may be different for GPs and DNs [16, 17], this study aims to compare the perceptions of participants and non-participants separately for each professional group. Second, this study aims to examine the association between PaTz-participation and care outcomes, by comparing the care provided to patients of GPs and DNs participating in a PaTz-group with the care provided to patients of GPs and DNs who are not.

\section{Methods \\ Design}

This study is part of a larger project aiming to improve palliative care in the primary care setting. In this project an assessment of the needs and experiences of GPs and DNs with palliative care was performed through an online questionnaire, available online from 5 April 2016 
until 5 August 2016. The results of this study were derived from this questionnaire.

\section{Study population}

Potential respondents were invited by professional associations, the national organization of palliative care networks (Fibula) and regional care support networks (ROS) through a call in newsletters and on their websites. Participating professional associations were the Dutch College of General Practitioners (NHG), the Advisory Board of General Practitioners on palliative care (PalHag) and the Dutch Nurses' Association (V\&VN). Respondents were eligible for inclusion if they: 1) were working as a GP or DN in patient care in the Netherlands, 2) had experience with palliative care. In order to assess the representativeness of the sample respondents they were compared to national figures for GPs and DNs on sex, age and working full or part time. The first question participants were asked was whether or not they had cared for a patient with a life-threatening illness or age-related decline in the final phase of their life. If so, they were presented with the rest of the questionnaire. If not, they had no access to the questionnaire.

\section{Measures}

For this study, a questionnaire on perceptions of $\mathrm{PaTz}$, and patient and care characteristics was created in which questions from previous primary palliative care research [18] were used where possible.

\section{Respondent characteristics}

Respondent demographic information included profession, age, gender, employment, years of practice and training in palliative care. After a description of the PaTz-method, respondents were asked whether they participated in PaTz and if not, whether they had heard of the method before.

\section{Perceptions of added value of PaTz and barriers to participation}

Respondents were asked to indicate to what extent they thought $\mathrm{PaTz}$ contributes to four aspects of palliative care provision [1]: knowledge [2], coordination [3], continuity and [4] collaboration. Respondents were also asked to indicate to what extent they thought five particular aspects are barriers to participation in PaTz. These aspects were [1]: time [2], financial aspects [3], administration [4], the desire to work alone, and [5] gathering a group of participants. For the purpose of analysis (ensuring sufficient observations in all categories), response options for both questions were: 'not at all, 'hardly,' 'partly', 'greatly' and 'don't know'. The answers were dichotomized by transforming the first two response options into 'no', and 'partly' and 'greatly' into 'yes'. Missing data was treated as 'don't know'. The data from these questions was analysed separately for GPs and DNs.

\section{Patient and care characteristics}

Next, respondents were to report on patient characteristics of their most recently deceased patient, such as age, gender and primary diagnosis and care characteristics, such as hospitalisations in the final two weeks, involved healthcare providers and whether or not the patient died in their preferred place of death. In addition, respondents were asked to report on interdisciplinary communication and communication with the patient, by presenting eight end-of-life topics, for which the respondents were asked to indicate whether they had discussed them with the patient and/or with another healthcare provider. These eight topics were: life expectancy, expected complications, (wishes regarding) hospital admissions, preferred place of death, (wishes regarding) palliative sedation, spiritual issues, treatment options, and (wishes regarding) euthanasia. GPs were asked if they had discussed the topics with a DNs, and vice versa. Again, missing data was treated as unknown.

\section{Statistical analyses}

Chi-square tests and independent sample t-tests were used to compare demographic information between GPs and DNs who participated in PaTz, and GPs and DNs who did not. Chi-square tests were also used to compare perceptions on the added value of and barriers for participation in PaTz between these two groups. Logistic regression analyses were used to compare the characteristics of patients described by either group, as well as the topics discussed and other care characteristics. First, crude logistic regression analysis were performed with being a $\mathrm{PaTz}$ participant or not as independent variable and the difference care characteristics as dependent variable. In order to adjust for healthcare provider characteristics that differed between health care providers who did and did not participate in $\mathrm{PaTz}$, we performed multivariable analyses in which these characteristics were added as independent variables. We present the results of these analyses as Odds Ratios with respective 95\%-confidence intervals. All statistical analyses were performed using SPSS, IBM Statistics for Windows version 22 .

\section{Results}

\section{Sample characteristics}

The characteristics of the 327 respondents are shown in Table 1 . The majority was female (86\%), and their mean age was 47 years. Most worked part-time (77\%), averaging $26 \mathrm{~h}$ per week. The mean years in practice 
Table 1 Characteristics of 327 Dutch respondents in the online questionnaire on PaTz-participation and palliative care

\begin{tabular}{|c|c|c|c|c|c|}
\hline \multirow[t]{2}{*}{ Characteristics $^{a}$} & \multirow{2}{*}{$\begin{array}{l}\text { Total } \\
N=327\end{array}$} & \multicolumn{2}{|c|}{ General practitioners $(n=98)$} & \multicolumn{2}{|c|}{ District nurses $(n=229)$} \\
\hline & & $\begin{array}{l}\mathrm{PaTz} \\
N=69(70 \%)\end{array}$ & $\begin{array}{l}\text { No PaTz } \\
N=29(30 \%)\end{array}$ & $\begin{array}{l}\mathrm{PaTz} \\
N=64(28 \%)\end{array}$ & $\begin{array}{l}\text { No PaTz } \\
N=165 \text { (72\%) }\end{array}$ \\
\hline Female gender, $\mathrm{N}(\%)$ & $280(86 \%)$ & $50(73 \%)$ & $17(59 \%)$ & 57 (91\%) & $156(95 \%)$ \\
\hline Age, (mean (SD)) & $47(10.6)$ & $50(8.5)$ & $47(8.9)$ & $46(11.3)$ & $46(11.1)$ \\
\hline Working part-time, N (\%) & $252(77 \%)$ & $51(74 \%)$ & $18(62 \%)$ & $37(58 \%)^{1}$ & $146(89 \%)^{1}$ \\
\hline Part-time hours per week, mean (SD) & $26(8.6)$ & $31(8.7)$ & $30(5.6)$ & $24(8.3)$ & $24(8.2)$ \\
\hline Working experience, mean years (SD) & $14(10.4)$ & $18(8.9)$ & $15(10.0)$ & $13(8.9)$ & $13(11.1)$ \\
\hline Training in palliative care, $\mathrm{N}(\%)$ & $190(58 \%)$ & 37 (54\%) & $14(48 \%)$ & $39(61 \%)$ & $100(61 \%)$ \\
\hline
\end{tabular}

${ }^{\mathrm{a}}$ Missing data $<5 \%$ for each variable

${ }^{1}$ Statistically significant difference found for 'working part-time' in DNs between $\mathrm{PaTz}$ and No PaTz $(p<0.001)$

was 14 (13 for DNs and 17 for GPs), and $58 \%$ of the respondents had received training in palliative care. GPs participated in a PaTz-group more often than DNs (70\% vs 28\%), while 23 and 35\% of the non-participating GPs and DNs had not heard of PaTz before. When comparing the characteristics between PaTzparticipants and non-participants, the only significant difference was found in DNs' employment: DNs not participating in $\mathrm{PaTz}$ more often worked part-time. Nationwide, the mean age of GPs is 48 years, and $51 \%$ are women [26], while the mean age of DNs is 45 years, and $92 \%$ are women [27]. Thus, compared with these national figures, our sample was of similar age while consisting of a high proportion of female GPs. While all respondents reported on the barriers and added value of $\mathrm{PaTz}, 98$ were unwilling to report on their most recently deceased patient.

\section{Perceptions of added value of PaTz and barriers to participation}

Table 2 provides GP and DN perceptions of added value of PaTz and barriers to participation in PaTz. The percentage of GPs and DNs perceiving added value of $\mathrm{PaTz}$ was relatively high for all four aspects of palliative care, ranging from an average of $85 \%$ for 'continuity' to $96 \%$ for 'knowledge' and 'collaboration'. Except for 'collaboration', no statistically significant differences between perceptions of added value of $\mathrm{PaTz}$ were found between GPs and DNs participating in PaTz and those who were not. Overall, 'time' was most often considered a barrier for participation (84\%), whereas 'desire to work alone' was least often perceived to hinder participation (16\%). When comparing perceptions of barriers between GPs, we found that non-participants more often perceived 'time' (100\% vs $88 \%)$ and 'administration' (73\% vs 50\%)

Table 2 Perceived added value of PaTz and perceived barriers for participation of 98 GPs and 229 DNs in the Netherlands

\begin{tabular}{|c|c|c|c|c|c|}
\hline \multirow[t]{2}{*}{ Aspect } & \multirow{2}{*}{$\begin{array}{l}\text { Total } \\
N=327 \\
\text { (yes } \\
(\%))\end{array}$} & \multicolumn{2}{|c|}{ General practitioners } & \multicolumn{2}{|c|}{ District nurses } \\
\hline & & $\begin{array}{l}\mathrm{PaTz} \\
N=69 \\
\text { (yes (\%)) }\end{array}$ & $\begin{array}{l}\text { No PaTz } \\
N=29 \\
\text { (yes (\%)) }\end{array}$ & $\begin{array}{l}\mathrm{PaTz} \\
N=64 \\
\text { (yes (\%)) }\end{array}$ & $\begin{array}{l}\text { No PaTz } \\
N=165 \\
\text { (yes (\%)) }\end{array}$ \\
\hline \multicolumn{6}{|l|}{ PaTz is of added value to ${ }^{a}$} \\
\hline Knowledge & $310(96)$ & $63(93)$ & $28(97)$ & $62(98)$ & $157(96)$ \\
\hline Collaboration & $303(96)$ & $66(99)^{1}$ & $26(90)^{1}$ & $63(98)$ & $148(95)$ \\
\hline Coordination & $279(88)$ & $55(83)$ & $24(83)$ & $60(94)$ & $140(89)$ \\
\hline Continuity & $270(85)$ & $51(76)$ & $18(64)$ & $57(92)$ & $144(90)$ \\
\hline \multicolumn{6}{|l|}{ Barrier for participation ${ }^{b}$} \\
\hline Time & $258(84)$ & $59(89)$ & $29(100)$ & $38(62)^{2}$ & $133(87)^{2}$ \\
\hline Finding a group & $179(66)$ & $31(53)$ & $19(70)$ & $28(50)^{2}$ & $101(78)^{2}$ \\
\hline Financial aspects & $166(62)$ & $33(51)$ & $17(68)$ & $28(50)^{3}$ & $88(72)^{3}$ \\
\hline Administration & $163(60)$ & $32(50)$ & $17(71)$ & $21(36)^{2}$ & $93(72)^{2}$ \\
\hline Desire to work alone & $42(16)$ & $7(11)$ & $2(8)$ & $5(9)^{4}$ & $28(22)^{4}$ \\
\hline
\end{tabular}

${ }^{\mathrm{a}}$ Missing data $<5 \%$ for all added values variables

${ }^{\mathrm{b}}$ Missing data for 'time' $<1 \%$, for other barrier variables between 13 and $14 \%$

${ }^{1}$ Statistically significant difference found for 'collaboration' in GPs $(p=0.046)$

${ }^{2}$ Statistically significant difference found for 'time', 'finding a group', and 'administration' in DNs $(p<0.001)$

${ }^{3}$ Statistically significant difference found for 'financial aspects in DNs $(p=0.004)$

${ }^{4}$ Statistically significant difference found for 'desire to work alone' $(p=0.044)$ 
as a barrier for participation than their participating colleagues. For 'financial aspects', 'the desire to work alone' and 'finding a group' we found no statistically significant difference. When comparing perceptions of barriers for participation between DNs, we found that non-participating DNs perceived all aspects as barrier for participation more often than DNs who were.

\section{Characteristics of patients described by PaTz-participants and non-participants}

The characteristics of the described patients are shown in Table 3. The mean age at death was 70-72 years, and $53-55 \%$ was female. Most patients were diagnosed with cancer $(62-70 \%)$, and the majority had been living at home (89-90\%). We found no statistically significant differences between the patients described by GPs and DNs participating in $\mathrm{PaTz}$ and those who were not in the crude nor in the adjusted analysis.

\section{Characteristics of care provided by PaTz-participants and non-participants}

Table 4 provides an overview of the topics discussed and care characteristics of the patients as described by the respondents and their relationship to PaTz-participation. Logistic regression analyses were adjusted for healthcare providers' profession (GP or DN) and employment (part-time or full-time). While some GPs and DNs had discussed $0-1(21-24 \%)$ and 2-4 of the topics (19-28\%) with another healthcare provider, a substantial part (37$44 \%$ ) had discussed 5 or more of the presented topics with another healthcare provider. Logistic regression analysis showed that PaTz-participation was significantly associated with discussing 5 or more topics $(\mathrm{OR}=2.55$, $95 \% \mathrm{CI}=1.11-5.88$ ). The same pattern applies to PaTzparticipation and the number of topics discussed with the patient. While few GPs and DNs (5-16\%) had discussed $0-1$ of the topics, and a minority $(11-15 \%)$ had discussed 2-4 topics, most GPs and DNs (69-84\%) had discussed 5 or more topics with the patient. Again, logistic regression analysis showed a significant association between PaTz-participation and discussing 5 or more topics $(\mathrm{OR}=3.16,95 \% \mathrm{CI}=1.04-9.64)$. Regarding the relationship between PaTz-participation and the discussion of specific topics, logistic regression analysis showed that PaTz-participation was significantly associated with discussing '(wishes regarding) palliative sedation' ( $\mathrm{OR}=$ $3.85,95 \% \mathrm{CI}=1.71-8.66)$ and '(wishes regarding) euthanasia' (OR $=2.97,95 \% \mathrm{CI}=1.48-5.97)$ with another healthcare provider. The significant associations between PaTz-participation and topics discussed with patients found in the crude analysis disappeared in the adjusted analysis, indicating that PaTz-participation was not

Table 3 Characteristics of patients described by 93 PaTz-participants and 142 non-PaTz-participants in the Netherlands

\begin{tabular}{|c|c|c|c|c|c|}
\hline Characteristics $^{a}$ & $\begin{array}{l}\text { Total } \\
(n=235)\end{array}$ & $\begin{array}{l}\mathrm{PaTz} \\
(n=93)\end{array}$ & No PaTz $(n=142)$ & $\begin{array}{l}\text { Crude OR } \\
(95 \% \mathrm{Cl})\end{array}$ & $\begin{array}{l}\text { Adjusted OR } \\
(95 \% \mathrm{Cl})\end{array}$ \\
\hline \multicolumn{6}{|l|}{ Age at death (years) } \\
\hline 65 or younger (ref) & $71(31 \%)$ & $28(31 \%)$ & $43(31 \%)$ & 1 & 1 \\
\hline $66-75$ & $60(26 \%)$ & $29(32 \%)$ & 31 (22\%) & $1.44(0.72-2.88)$ & $1.12(0.51-2.43)$ \\
\hline $76-85$ & $60(26 \%)$ & $20(22 \%)$ & $40(29 \%)$ & $0.77(0.38-1.57)$ & $0.69(0.31-1.53)$ \\
\hline 86 or older & $40(17 \%)$ & $14(15 \%)$ & $26(19 \%)$ & $0.83(0.37-1.85)$ & $0.73(0.29-1.85)$ \\
\hline Gender (\% female) & $55 \%$ & 53 & 55 & $0.92(0.54-1.6)$ & $0.76(0.42-1.4)$ \\
\hline \multicolumn{6}{|l|}{ Diagnosis } \\
\hline Cancer (ref) & $153(65 \%)$ & 65 (70\%) & $88(62 \%)$ & 1 & 1 \\
\hline Cardiovascular disease & $4(2 \%)$ & $2(2 \%)$ & $2(1 \%)$ & $1.4(0.19-9.9)$ & $0.83(0.07-10.3)$ \\
\hline COPD & $8(3 \%)$ & $3(3 \%)$ & $5(4 \%)$ & $0.81(0.19-3.5)$ & $1.3(0.26-6.0)$ \\
\hline Stroke & $3(1 \%)$ & 0 & $3(2 \%)$ & 0 & 0 \\
\hline Dementia & $2(1 \%)$ & $1(1 \%)$ & $1(1 \%)$ & $1.4(0.08-22.1)$ & $1.3(0.06-30.5)$ \\
\hline Frailty/age-related decline & $10(4 \%)$ & $3(3 \%)$ & $7(5 \%)$ & $0.58(0.14-2.3)$ & $1.2(0.27-5.3)$ \\
\hline Multi-morbidity & $53(23 \%)$ & $18(19 \%)$ & $35(25 \%)$ & $0.70(0.36-1.3)$ & $0.81(0.39-1.7)$ \\
\hline Other & $2(1 \%)$ & $1(1 \%)$ & $1(1 \%)$ & $1.4(0.08-22.1)$ & $3.5(0.21-58.3)$ \\
\hline \multicolumn{6}{|l|}{ Setting } \\
\hline Home (ref) & $191(90 \%)$ & 75 (89\%) & 116 (90\%) & 1 & 1 \\
\hline Residential care home & $12(6 \%)$ & $3(4 \%)$ & $9(7 \%)$ & $0.52(0.14-2.0)$ & $0.27(0.06-1.2)$ \\
\hline Hospice & $10(5 \%)$ & $6(7 \%)$ & $4(3 \%)$ & $2.3(0.63-8.5)$ & $2.0(0.48-8.4)$ \\
\hline
\end{tabular}

${ }^{\mathrm{a}}$ Missing data $<2 \%$ for each variable

${ }^{\mathrm{b}} \mathrm{OR}=$ Odds ratio

${ }^{\mathrm{C}}$ Adjusted for healthcare providers' profession (GP or DN) and employment (part-time or full-time) 
Table 4 Results from logistic regression analyses estimating the association between PaTz-participation and characteristics of palliative care provided to their most recently deceased patient by 235 Dutch healthcare providers

\begin{tabular}{|c|c|c|c|c|c|}
\hline Care characteristics $^{\mathrm{a}}$ & Total $(n=235)$ & $\operatorname{PaTz}(n=93)$ & No PaTz $(n=142)$ & Crude OR $(95 \% \mathrm{CI})$ & Adjusted OR ${ }^{\mathrm{b}}(95 \% \mathrm{Cl})$ \\
\hline \multicolumn{6}{|c|}{ Number of topics discussed with another healthcare provider } \\
\hline $0-1$ topics & $63(27 \%)$ & $26(28 \%)$ & $37(26 \%)$ & 1 & 1 \\
\hline $2-4$ topics & $78(33 \%)$ & $26(28 \%)$ & $52(37 \%)$ & $0.71(0.26-1.42)$ & $1.31(0.57-2.99)$ \\
\hline $5-8$ topics & $94(40 \%)$ & $41(44 \%)$ & $53(37 \%)$ & $1.10(0.58-2.10)$ & $2.55(1.11-5.88)^{*}$ \\
\hline \multicolumn{6}{|c|}{ Topics discussed with another healthcare provider } \\
\hline Life expectancy & $150(64 \%)$ & $60(65 \%)$ & $90(63 \%)$ & $1.05(0.61-1.81)$ & $1.75(0.91-3.37)$ \\
\hline Expected complications & $137(58 \%)$ & $57(61 \%)$ & $80(56 \%)$ & $1.23(0.72-2.09)$ & $1.41(0.75-2.63)$ \\
\hline (Wishes regarding) palliative sedation & $137(58 \%)$ & $57(61 \%)$ & $80(56 \%)$ & $1.23(0.72-2.09)$ & $3.85(1.71-8.66)^{* *}$ \\
\hline (Wishes regarding) hospital admission & $113(48 \%)$ & $46(50 \%)$ & $67(47 \%)$ & $1.10(0.65-1.85)$ & $1.60(0.86-2.98)$ \\
\hline Treatment options & $107(46 \%)$ & $40(43 \%)$ & $67(47 \%)$ & $0.85(0.50-1.43)$ & $1.24(0.66-2.30)$ \\
\hline Preferred place of death & $102(43 \%)$ & $43(46 \%)$ & $59(42 \%)$ & $1.21(0.71-2.05)$ & $1.70(0.91-3.17)$ \\
\hline (Wishes regarding) euthanasia & $82(35 \%)$ & $37(40 \%)$ & $45(32 \%)$ & $1.42(0.83-2.46)$ & $2.97(1.48-5.97)^{* *}$ \\
\hline Spiritual issues & 45 (19\%) & $17(18 \%)$ & $28(20 \%)$ & $0.91(0.47-1.78)$ & $1.41(0.66-3.01)$ \\
\hline \multicolumn{6}{|l|}{ Number of topics discussed with patient } \\
\hline $0-1$ topics & $28(12 \%)$ & $5(5 \%)$ & $23(16 \%)$ & 1 & 1 \\
\hline $2-4$ topics & $31(13 \%)$ & $10(11 \%)$ & $21(15 \%)$ & $2.19(0.64-7.46)$ & $2.95(0.77-11.3)$ \\
\hline $5-8$ topics & $176(75 \%)$ & 78 (84\%) & $98(69 \%)$ & $3.66(1.33-10.1)^{*}$ & $3.16(1.04-9.64)^{*}$ \\
\hline \multicolumn{6}{|l|}{ Topics discussed with patient } \\
\hline Life expectancy & $191(81 \%)$ & 79 (85\%) & $112(79 \%)$ & $1.51(0.75-3.03)$ & $1.21(0.56-2.63)$ \\
\hline Expected complications & $161(69 \%)$ & $71(76 \%)$ & $90(63 \%)$ & $1.87(1.04-3.36)^{*}$ & $1.60(0.84-3.07)$ \\
\hline (Wishes regarding) hospital admission & 185 (79\%) & $82(88 \%)$ & $103(73 \%)$ & $2.82(1.36-5.85)^{* *}$ & $1.68(0.75-3.74)$ \\
\hline Preferred place of death & 185 (79\%) & $80(86 \%)$ & 105 (74\%) & $2.17(1.08-4.35)^{*}$ & $2.05(0.95-4.41)$ \\
\hline (Wishes regarding) palliative sedation & $168(72 \%)$ & 75 (81\%) & $93(66 \%)$ & $2.20(1.18-4.08)^{*}$ & $1.70(0.86-3.36)$ \\
\hline Spiritual issues & $155(66 \%)$ & $62(67 \%)$ & $93(66 \%)$ & $1.05(0.61-1.83)$ & $1.17(0.63-2.18)$ \\
\hline Treatment options & $164(70 \%)$ & 72 (77\%) & $92(65 \%)$ & $1.86(1.03-3.38)^{*}$ & $1.24(0.64-2.43)$ \\
\hline (Wishes regarding) euthanasia & $144(61 \%)$ & $68(73 \%)$ & $76(54 \%)$ & $2.36(1.34-4.16)^{* *}$ & $1.56(0.83-2.94)$ \\
\hline \multicolumn{6}{|c|}{ Healthcare provider expecting the patient's death } \\
\hline More than 6 months in advance (ref) & $52(22 \%)$ & $23(25 \%)$ & $29(21 \%)$ & 1 & 1 \\
\hline 3-6 months in advance & $68(29 \%)$ & $29(31 \%)$ & $39(28 \%)$ & $0.94(0.45-1.94)$ & $1.19(0.51-2.74)$ \\
\hline $1-2$ months in advance & $41(18 \%)$ & $14(15 \%)$ & $27(19 \%)$ & $0.65(0.28-1.52)$ & $0.83(0.31-2.17)$ \\
\hline In the final month & 45 (19\%) & $17(18 \%)$ & $28(20 \%)$ & $0.77(0.34-1.73)$ & $1.63(0.64-4.13)$ \\
\hline In the final week & $27(12 \%)$ & $10(11 \%)$ & $17(12 \%)$ & $0.74(0.29-1.93)$ & $1.53(0.52-4.51)$ \\
\hline Hospital admission in the final 2 weeks & $45(19 \%)$ & $20(22 \%)$ & $25(18 \%)$ & $1.26(0.65-2.43)$ & $1.60(0.77-3.35)$ \\
\hline Preferred place of death known & $226(96 \%)$ & 89 (96\%) & $137(96 \%)$ & $1.30(0.23-7.24)$ & $0.95(0.15-5.93)$ \\
\hline Died at preferred place of death & $219(93 \%)$ & 85 (91\%) & 134 (94\%) & $0.48(0.10-2.18)$ & $0.76(0.15-3.95)$ \\
\hline \multicolumn{6}{|l|}{ Place of death } \\
\hline Home (ref) & 175 (75\%) & 72 (78\%) & $103(74 \%)$ & 1 & 1 \\
\hline Residential care home & $18(8 \%)$ & $5(5 \%)$ & $13(9 \%)$ & $0.55(0.19-1.61)$ & $0.59(0.18-1.93)$ \\
\hline Hospice & $27(12 \%)$ & $10(11 \%)$ & $17(12 \%)$ & $0.84(0.36-1.94)$ & $0.76(0.30-1.93)$ \\
\hline Hospital & $8(3 \%)$ & $4(4 \%)$ & $4(3 \%)$ & $1.43(0.35-5.91)$ & $0.88(0.18-4.26)$ \\
\hline Other/don't know & $4(2 \%)$ & $1(1 \%)$ & $3(2 \%)$ & $0.48(0.05-4.67)$ & $0.33(0.03-3.95)$ \\
\hline
\end{tabular}

${ }^{\mathrm{a}}$ Missing data $<2 \%$ for all variables

${ }^{\mathrm{b}}$ Adjusted for healthcare providers' profession (GP or DN) and employment (part-time or full-time)

* $p<0.05 * * p<0.01$ 
associated with the discussion of particular topics with patients.

Considering the other care characteristics, no significant differences were found between PaTz-participants and non-participants. Around half (49-56\%) of the GPs and DNs expected the patients' death 3 months in advance or earlier while a minority (11-12\%) did not expect the patient's death until the final week. Further, almost all GPs and DNs (97-98\%) were aware of their patient's preferred place of death and the vast majority of patients (93-95\%) died at their preferred place. Most patients $(74-78 \%)$ died at home, and even though one fifth $(18-22 \%)$ patients was admitted to a hospital in the final 2 weeks, only a small minority (3-4\%) died there. Logistic regression analysis showed no significant association between PaTz-participation and any of these care characteristics.

\section{Discussion}

\section{Summary of findings}

Respondents considered PaTz to be of value on all four prompted aspects: knowledge, coordination, continuity of care and collaboration. A lack of time was considered the most important barrier for participation in PaTz, but financial aspects, administrative burden and having to find a group to participate in were also perceived as barriers by the majority of respondents. While we found an association between participating in a PaTz-group and discussing more topics with another healthcare provider and with patients, we found no associations between PaTz-participation and other care characteristics.

\section{Strengths and limitations of this study}

A strength of this study is that, contrary to prior evaluation studies, a control group was included. Still, even though the cross-sectional design of this study can demonstrate associations between $\mathrm{PaTz}$ and care outcomes, it is not suitable to demonstrate causality. Another limitation of this study lies in the recruitment strategy. While our recruitment strategy enabled GPs and DNs from all over the country to participate, it does not allow for response rates to be calculated. Also, as the care characteristics were self-reported by GPs and DNs, recall bias could play a role and the patient perspective is underexposed. Finally, it is possible GPs and DNs interested in palliative care are overrepresented in the sample. This could lead to an overly positive image of palliative care in the primary care setting, and an underestimation of the effect of PaTz.

\section{Comparison and reflection}

A large majority of both participants and non-participants recognized the benefits of $\mathrm{PaTz}$ regarding knowledge, coordination, continuity and collaboration. PaTz- participants, particularly nurses, generally saw fewer barriers for participation, but regardless of participation or profession, it is clear that a lack of time is the most important one. It is possible that participating in a PaTzgroup leads to reduced barrier perception, but it could also be the other way around: participation requires reduced barrier perception. However it may be, the reduced barrier participation and unchanging added value perception of PaTz-participants can be used in the promotion of PaTz. Still, further in-depth qualitative exploration of the benefits of PaTz, how to increase value and how to remove barriers for participation is recommended.

Further, the results showed that, like participating in the GSF [28], PaTz-participation seems to be associated with improved communication with other healthcare providers as PaTz-participants more often discussed 5 or more topics relevant to palliative care than non-participants. Similarly, as PaTz-participants more often discussed 5 or more topics with their patient, PaTz-participation seems to be associated with improved communication with the patients. As endof-life communication between GPs and DNs and with patients is crucial to the delivery of adequate palliative care $[12,13,29,30]$, these are important findings.

Still, beside the number of topics discussed, we found no differences in care characteristics. A ceiling effect, as suggested by Van der Plas [18], could be the cause, as the level of palliative care provided was generally high. Over two thirds of the respondents expected the patients' death more than a month in advance, providing time to plan and deliver effective end-of-life care [31]. Also, nearly all respondents were aware of the preferred place of death of the patient (96\%), even though the percentage of GPs and DNs that reported to have discussed the topic with the patient was somewhat lower at $74-86 \%$. Finally, most patients died at their preferred place (93\%). Despite being self-reported and the possibility of recall bias, these numbers are impressive compared to earlier studies, where the patients preferred place of death was known in $54-60 \%$ of the cases and approximately $80 \%$ died at their preferred place [32, 33]. This high level of palliative care may not be representative for the general level of palliative care in primary care, and healthcare providers with less affinity for palliative care may benefit more from PaTz. It should also be mentioned that, for reasons unknown to us, 30\% of the respondents did not report on their most recent case. Next to merely not wanting to spent more time on the questionnaire it is also possible that for some their most recent case concerned patients where the care was managed less than ideal. Further, it is 
possible that respondents who did provide patient and care details, reported on a recent patient whose care was managed well, rather than their actual most recent case.

Overall, while this study has shown a few promising associations, we recommend future research to focus on the effect of PaTz on tangible care outcomes in a design suitable to show causality, and on the perspective of patients and relatives on the care provided and how to facilitate participation and remove barriers in a qualitative manner.

\section{Conclusions and practical implications}

Confirming the previously reported perception of participants that $\mathrm{PaTz}$ improves communication in palliative care $[17,18]$, this article adds to the body of evidence of the value of PaTz in the primary care setting. As communication with other healthcare providers and with patients is key in palliative care [12, 34], participating in $\mathrm{PaTz}$ can aid healthcare providers in their task. Tailored to country-specific health care systems, this may also be in the case in other countries where generalists are the primary palliative care providers, like Canada, Australia, Belgium, Italy and Spain [35-37].

Our study also shows that further implementation of PaTz is barred by GPs' and DNs' perceived lack of time, and financial compensation and involves additional administrative red tape. Targeted promotion of $\mathrm{PaTz}$ by colleagues sharing success stories and positive experiences and firm evidence of its effects, could facilitate adoption of the method. In addition, as PaTz is more likely to benefit healthcare providers with less affinity with palliative care, implementation of $\mathrm{PaTz}$ in that particular group deserves extra attention.

\section{Abbreviations}

DN: District nurse; GP: General practitioner; GSF: Gold Standards Framework: OR: Odds Ratio; PaTz: PAlliatieve ThuisZorg (palliative care at home)

\section{Acknowledgements}

We would like to thank Yasin Bahar for his work in the exploratory analysis of the data.

\section{Ethical approval and consent to participate}

The Medical Ethics Committee of the VUmc approved of this study in advance (METc VUmc 2016.320). The purpose and content of the survey, as well as the option to pause or stop participation at any time, were explained with the invitation. Informed consent was assumed upon participation in the survey.

\section{Authors' contributions}

IK, RP, BS and BO designed the study. IK performed the analyses and interpretation of the data from the online survey, which were discussed with all other authors. All authors contributed to the manuscript, and all authors read and approved the final manuscript.

\section{Funding}

This study was funded by ZonMW (project number 844001102). The funder had no role in the design of the study, the selection of respondents, the collection, analysis or interpretation of data, decision to publish or preparation of the manuscript.

\section{Availability of data and materials}

The dataset used and analysed during the current study are available from the corresponding author on reasonable request.

\section{Consent for publication}

Not applicable.

\section{Competing interests}

B Schweitzer is medical advisor to the PaTz-foundation.

B Onwuteaka-Philipsen is director of the PaTz-foundation.

All other authors declare that they have no competing interests.

Received: 3 January 2019 Accepted: 24 July 2019

Published online: 03 August 2019

\section{References}

1. WHO. Definition of Palliative Care: World Health Organisation; 2017 [14-82017]. Available from: http://www.who.int/cancer/palliative/definition/en/.

2. Centeno C, Bolognesi D, Biasco G. Comparative analysis of specialization in palliative medicine processes within the World Health Organization European region. J Pain Symptom Manag. 2015;49(5):861-70.

3. Quill TE, Abernethy AP. Generalist plus specialist palliative care--creating a more sustainable model. N Engl J Med. 2013;368(13):1173-5.

4. Evans N, Costantini M, Pasman HR, Van den Block L, Donker GA, Miccinesi G, et al. End-of-life communication: a retrospective survey of representative general practitioner networks in four countries. J Pain Symptom Manag. 2014:47(3):604-19.e3.

5. Eizenga W, De Bont M, Vriezen J, Jobse A, Kruyt J, Lampe I, et al. Landelijke Eerstelijns Samenwerkings Afspraak Palliatieve zorg [national agreement on collaboration in palliative care in primary care]. Huisarts Wet. 2006;49(6):308-12.

6. Koper I, Pasman HRW, Onwuteaka-Philipsen BD. Experiences of Dutch general practitioners and district nurses with involving care services and facilities in palliative care: a mixed methods study. BMC Health Serv Res. 2018;18(1):841.

7. McLaren G, Preston C. Evidence based palliative care. General palliative care should be evaluated. BMJ. 1999;319:1573.

8. Morrison I, Smith R. Hamster health care : time to stop running faster and redesign health care. BMJ. 2000;321(7276):1541-2.

9. Goetz K, Musselmann B, Szecsenyi J, Joos S. The influence of workload and health behavior on job satisfaction of general practitioners. Fam Med. 2013; 45(2):95-101.

10. Pype P, Peersman W, Wens J, Stes A, Van den Eynden B, Deveugele M. What, how and from whom do health care professionals learn during collaboration in palliative home care: a cross-sectional study in primary palliative care. BMC Health Serv Res. 2014;14:501.

11. Mitchell S, Loew J, Millington-Sanders C, Dale J. Providing end-of-life care in general practice: findings of a national GP questionnaire survey. $\mathrm{Br} J \mathrm{Gen}$ Pract. 2016;66(650):e647-53.

12. Brighton $L$, Bristowe K. Communication in palliative care: talking about the end of life, before the end of life. Postgrad Med J. 2016;92(1090):466-70.

13. Wright AA, Zhang B, Ray A, Mack JW, Trice E, Balboni T, et al. Associations between end-of-life discussions, patient mental health, medical care near death, and caregiver bereavement adjustment. JAMA. 2008;300(14):1665-73.

14. Trice ED, Prigerson HG. Communication in end-stage cancer: review of the literature and future research. J Health Commun. 2009;14(Suppl 1):95-108.

15. Slort W, Schweitzer BP, Blankenstein AH, Abarshi EA, Riphagen II, Echteld MA, et al. Perceived barriers and facilitators for general practitioner-patient communication in palliative care: a systematic review. Palliat Med. 2011; 25(6):613-29.

16. Shaw KL, Clifford C, Thomas K, Meehan H. Review: improving end-of-life care: a critical review of the gold standards framework in primary care. Palliat Med. 2010;24(3):317-29.

17. van der Plas AG, Hagens M, Pasman HR, Schweitzer B, Duijsters M, Onwuteaka-Philipsen BD. PaTz groups for primary palliative care: reinventing cooperation between general practitioners and district nurses in palliative care: an evaluation study combining data from focus groups and a questionnaire. BMC Fam Pract. 2014;15:14. 
18. van der Plas AG, Pasman HRW, Schweitzer B, Onwuteaka-Philipsen BD. Improving palliative care provision in primary care: a pre- and post-survey evaluation among PaTz groups. Br J Gen Pract. 2018;68(670):e351-e9.

19. Rogers EM. Diffusion of innovations. 5th ed. New York: Free Press; 2003.

20. Thomas K, Clifford C, Wilson JA. Summary evaluation of effectiveness for gold standards framework primary care: National Gold Standards Framework Centre; 2016. [Available from: http://www. goldstandardsframework.org.uk/evidence

21. Meier EA, Gallegos JV, Montross-Thomas LP, Depp CA, Irwin SA, Jeste DV Defining a good death (successful dying): literature review and a call for research and public dialogue. Am J Geriatr Psychiatry. 2016;24(4):261-71.

22. Reyniers T, Houttekier D, Cohen J, Pasman HR, Deliens L. The acute hospital setting as a place of death and final care: a qualitative study on perspectives of family physicians, nurses and family carers. Health Place. 2014;27:77-83.

23. Ko W, Beccaro M, Miccinesi G, Van Casteren V, Donker GA, OnwuteakaPhilipsen B, et al. Awareness of general practitioners concerning cancer patients' preferences for place of death: evidence from four European countries. Eur J Cancer. 2013;49(8):1967-74.

24. Meeussen K, Van den Block L, Bossuyt N, Bilsen J, Echteld M, Van Casteren V, et al. GPs' awareness of patients' preference for place of death. Br J Gen Pract. 2009:59(566):665-70.

25. Stewart MA. Effective physician-patient communication and health outcomes: a review. CMAJ. 1995;152(9):1423-33.

26. Van der Velden LFJ, Kasteleijn A, Kenens RJ. Cijfers uit de registratie van huisartsen Utrecht: Nivel; 2017 [Available from: https:/www.nivel.nl/sites/ default/files/cijfers-uit-de-registratie-van-huisartsen-peiling-januari-2016.pdf.

27. Kalkhoven F, Van der Aalst M. De zorg. Sectorbeschrijving. Amsterdam: UWV; 2015. [Available from: https://www.uwv.nl/overuwv/lmages/ Sectorbeschrijving\%20Zorg\%20def2.pdf

28. Mahmood-Yousuf K, Munday D, King N, Dale J. Interprofessional relationships and communication in primary palliative care: impact of the gold standards framework. Br J Gen Pract. 2008;58(549):256-63.

29. Wilson E, Seymour J. The importance of interdisciplinary communication in the process of anticipatory prescribing. Int J Palliat Nurs. 2017;23(3):129-35.

30. Forrest S, Barclay S. Palliative care: a task for everyone. Br J Gen Pract. 2007;57(539):503.

31. Kennedy C, Brooks-Young P, Brunton Gray C, Larkin P, Connolly M, WildeLarsson B, et al. Diagnosing dying: an integrative literature review. BM. Support Palliat Care. 2014;4(3):263-70.

32. Abarshi E, Onwuteaka-Philipsen B, Donker G, Echteld M, Van den Block L, Deliens $L$. General practitioner awareness of preferred place of death and correlates of dying in a preferred place: a nationwide mortality follow-back study in the Netherlands. J Pain Symptom Manag. 2009;38(4):568-77.

33. De Roo ML, Miccinesi G, Onwuteaka-Philipsen BD, Van Den Noortgate N, Van den Block L, Bonacchi A, et al. Actual and preferred place of death of home-dwelling patients in four European countries: making sense of quality indicators. PLoS One. 2014;9(4):e93762.

34. Faulkner A. ABC of palliative care: communication with patients, families, and other professionals. BMJ. 1998:316:130-2.

35. Pivodic L, Pardon K, Van den Block L, Van Casteren V, Miccinesi G, Donker GA, et al. Palliative care service use in four European countries: a crossnational retrospective study via representative networks of general practitioners. PLoS One. 2013:8(12):e84440.

36. Johnson CE, Girgis A, Paul CL, Currow DC. Palliative care referral practices and perceptions: the divide between metropolitan and non-metropolitan general practitioners. Palliat Support Care. 2011;9(2):181-9.

37. Brown CRL, Hsu AT, Kendall C, Marshall D, Pereira J, Prentice M, et al. How are physicians delivering palliative care? a population-based retrospective cohort study describing the mix of generalist and specialist palliative care models in the last year of life. Palliat Med. 2018;32(8):1334-43.

\section{Publisher's Note}

Springer Nature remains neutral with regard to jurisdictional claims in published maps and institutional affiliations.

\section{Ready to submit your research? Choose BMC and benefit from:}

- fast, convenient online submission

- thorough peer review by experienced researchers in your field

- rapid publication on acceptance

- support for research data, including large and complex data types

- gold Open Access which fosters wider collaboration and increased citations

- maximum visibility for your research: over $100 \mathrm{M}$ website views per year

At BMC, research is always in progress.

Learn more biomedcentral.com/submissions 